(2) Open Access Full Text Article

\title{
Potential liability for universities and university faculty researching emerging technologies at the nanoscale
}

\author{
Patrick AS Mills' \\ David K Mills² \\ 'OrganicNANO, Monroe, ${ }^{2}$ School \\ of Biological Sciences, Center \\ for Biomedical Engineering and \\ Rehabilitation Science, Louisiana Tech \\ University, Ruston, LA, USA
}

This article was published in the following Dove Press journal:

Medicolegal and Bioethics

7 July 2017

Number of times this article has been viewed

\begin{abstract}
In this article, an entrepreneur and a researcher discuss the potential short- and long-term liability concerns that may arise for both research institutions and research faculty involved in studying materials whose health risks due to periods of varied exposure are currently unknown. Particular attention is paid to the case of high aspect ratio nanoparticles (HARNs), which studies have demonstrated to be analogous to asbestos fibers. This article first examines the case of HARNs and establishes the danger inherent in persons working with such particles and in the consuming public. It then discusses the current law as established regulating the relationship between university students working in a research laboratory, supervising faculty, and university and current causes of action that have been established in tort for injured students. It considers scenarios that might arise out of emerging nanoscale research, using HARN particle research as an example, to discuss how liability might arise for research institutions and research faculty. Finally, the article concludes with suggestions for possible courses of action universities could take to protect themselves against this type of liability.
\end{abstract}

Keywords: liability, nanotechnology, high aspect ratio nanoparticles, commercial development, nanoparticles, nanotoxicity

\section{Introduction}

\section{Background}

What happens when current scientific protocols or understanding proves inadequate to protect individuals from significant harm? This situation has occurred before. Consider the case of the drug, thalidomide. According to Greek, any amount of animal testing using the protocols of that era would not have prevented the thalidomide disaster, irrespective of negligent or willful misconduct on the part of the drug's developers. ${ }^{1}$ Consequently, thalidomide was widely prescribed for morning sickness, and tens of thousands of congenital disabilities resulted. ${ }^{2}$ Today, the standard of care is not to administer drugs to pregnant women unless necessary to save their life, thus avoiding any risk of embryonic development. ${ }^{1}$ However, thalidomide's developer, Chemie Grünenthal, remains in litigation $>50$ years after the fact., ${ }^{3,4}$ The US Food and Drug Administration regulations and consumer protections - as well as the mass tort law - have taken great strides since the thalidomide crisis of the 1950 s and the $1960 \mathrm{~s} .{ }^{5}$ However, the nature of science is to research unknown quantities, and, therefore, the risk remains that something understood as harmless today - no matter how much well-intentioned legislation or precaution is taken - can emerge as the thalidomide of tomorrow.

While law and liability issues involving consumers and the general public have been the subject of significant research, a poorly documented subject is the scenario involving 
university research conducted in an area of emerging science or technology that results in harm to the researcher in the near or long term. ${ }^{6-8}$ Marie Curie's life is well known and remains a cautionary tale - the story of a devoted scientist who, the world and she both uncertain of the side effects of radiation, died quite young from exposure to the very elements she sought to understand. ${ }^{9}$ Madame Curie even enacted health regulations to protect her research staff. ${ }^{9}$ However, her research killed her nonetheless. Her case, and that of the university faculty in general, can perhaps be written away under the sophisticated user legal doctrine. As professional scientists, faculty are expected to "publish or perish", reap the rewards of their research, and - as professionals in their field of study - should recognize potential risks inherent in their research and act to minimize them accordingly. ${ }^{10}$ In this way, university faculty are analogous to the boxer who steps into the ring conscious and consenting to the possibility that he may be injured. ${ }^{11}$ Universities, therefore, owe a diminished duty - or no duty - to protect the faculty from harm resulting from exposure to novel materials they chose to research. Further, faculty exposure will often be the result of their negligence. What, however, does the law make regarding the case of students - graduate or undergraduate - working in the laboratories of university faculty? Can the sophisticated user doctrine be applied to them as well?

At present, nanoscale research - or the fields of nanotechnology, nanomedicine, nanotheranostics, and so on - stands as one of the fastest growing emerging fields of scientific and medical study, regarding both academic interest (grant dollars awarded) and commercial interest (corporate investment/ technology transfer). Since President Clinton authorized the National Nanotechnology Initiative, $>\$ 20$ billion has been earmarked by the government for nanoscale research. ${ }^{12}$ Additionally, market research studies indicate that the worldwide market for nanoscale products will exceed $\$ 3$ trillion by $2020 .{ }^{13}$ At the same time, however, studies have uncovered disconcerting qualities in nanoparticles - especially the class known as high aspect ratio nanoparticles (HARNs) discussed herein - qualities such as similarities in structure to asbestos fibers. ${ }^{14,15}$ Given the incredible and sustained growth of this research field - estimated at 19\% between 2013 and 2017 by one report - it stands to reason that the rate of discovery may outpace the scientific community's capacity to establish protocols for the secure handling of emerging materials or to determine these materials' long-term effects on the human body. ${ }^{16-18}$ As demonstrated in the case of thalidomide - and so many other drugs or technologies rushed to market financial considerations can override ethics under the best of circumstances. Universities and university faculty, given the opportunities presented by commercialization or technol- ogy transfer, are not immune to these same market forces. As such, it is paramount that research institutions and their faculty understand the potential liability they may face under varying circumstances - from accidental to negligent to willful - where students are exposed to materials with unknown long-term effects due to a current lack of scientific understanding. By understanding these risks, universities and their faculty will not only be able to mitigate their risks of potential liability but also establish or maintain the best practices within their laboratory environments, thus ensuring the short- and long-term safety of their students.

\section{Research question}

This paper seeks to address the practical and legal implications for universities and their faculty when conducting research in emerging fields where the health effects of materials associated with these studies are not currently understood by medical science. While the faculty in question can be considered to qualify as sophisticated users in terms of their research, the issues of liability where students are injured while acting under the direction of university faculty are less established. ${ }^{11,19,20}$ Though this paper seeks to establish a legal theory and best practices relevant to any material of unknown quantity, this paper will examine HARN nanotechnologies in considering the issue of potential liability for injurious effects to student researchers from exposure to nanoscale materials.

This research question is of critical importance to universities as novel materials such as HARNs continue to be researched by growing numbers of faculty and students worldwide. ${ }^{21}$ According to estimates, the total of payouts to all plaintiffs in asbestos litigation may exceed $\$ 275$ billion in the USA alone. ${ }^{22}$ Grünenthal, the German pharmaceutical company that developed thalidomide first, settled lawsuits in Germany stemming from resultant congenital disabilities in $1970 .{ }^{23}$ In 2013 , the company was ordered to pay the Spanish victims group called Avite a settlement worth millions of euros. ${ }^{24}$ In August 2012, Grünenthal was criticized for its action in unveiling a statue honoring the victims of thalidomide; despite $>50$ years having passed, this one action continues to harm the company in both financial and reputational terms. ${ }^{25}$

Researching novel materials presents systematic risks to those involved that can have longstanding, negative consequences for the institutions that do not properly insure themselves against this risk. Universities, therefore, must plan accordingly to ensure they do not become the next Grünenthal or Johns Manville. ${ }^{26}$

This paper first discusses the basic science of HARN nanotechnologies, the qualities of these particles that make 
them of particular concern to health and regulatory agencies, and how these inherent dangers can be extended to the scenario of any current or future research material with unknown health consequences. Then, it outlines the law as established between the university and the student, established causes of action, and potential causes of action that might arise under ordinary and extraordinary scenarios. Finally, it suggests the mitigating actions that universities should take to limit their exposure to potential liability and protect the welfare of their student researchers.

\section{Risk inherent in emerging technologies \\ Nanomaterials and HARNs explained}

What are nanomaterials? While definitions vary, scientists generally agree that nanomaterials have structured components with at least one dimension measured on the nanoscale or in nanometers, that is, one-millionth of a millimeter. ${ }^{27}$ HARNs are a class of nanomaterials; the best known and most widely researched HARNs are carbon nanotubes (CNTs). ${ }^{14}$

How do nanomaterials differ from bulk materials? First, nanoparticulate matter possesses a higher ratio of surface area to volume, dramatically enhancing the surface area for chemical reactions; this increase can be as large as 1000 -fold. ${ }^{28}$ Second, nanomaterials exhibit a quantum effect on the confinement of electrons that may result in a quantized energy spectrum, magnetic moments in materials otherwise nonmagnetic in bulk, and changes in electron affinity. ${ }^{28}$ These differences afford nanomaterials a set of commercially, industrially, and medically useful characteristics dissimilar to materials taking more traditional solid, liquid, gaseous, or plasma forms of matter. ${ }^{29}$

What are CNTs? CNTs are "unique nanometer-scale structures based on a graphene cylinder, typically a few nanometers in diameter, which can range in length from a few micrometers to millimeters". ${ }^{30}$ CNTs come in forms such as fibers and as more compact particles. Industry finds CNTs of interest because they possess unique qualities such as being significantly stronger and lighter than steel, having efficiency in conducting electricity and heat, and having the ability to act as semiconductors, among other characteristics. ${ }^{31}$ They have become a valuable industrial product.

\section{HARN danger to workers and consumers}

Why are HARNs of concern to health and environmental safety organizations and researchers? HARNs worry many because they fit the asbestos model of pathogenicity and exposure to asbestos has been determined as a causal agent in a number of diseases of the lung and the pleura, one of the two membranes around the lungs. ${ }^{32}$ Research on the pathogenicity of asbestos has yielded three basic characteristics central to whether exposure to asbestos fibers is dangerous for humans: dimension, durability, and dosage. ${ }^{32}$

Dimension is critical because particle shape determines how the human body processes foreign material. ${ }^{32}$ Diameter affects the ability of fiber particles to penetrate beyond the ciliated airways deeper into the lungs where deposition can have injurious effects; thin fibers are more aerodynamic and have an easier time clearing the ciliated airways. ${ }^{33}$ Fiber length is also critical because fibers longer than $15 \mu \mathrm{m}$ cannot be processed by macrophages via phagocytosis. ${ }^{33}$ This "frustrated" phagocytosis results in a process leading to the induction of tumor necrosis factor-alpha that plays a critical role in the development of pulmonary fibrosis. ${ }^{34}$

Durability is the second factor in fiber pathogenicity. ${ }^{32}$ It refers to how soluble a fiber is or how readily the human body can break down a fiber; durable fibers are nonsoluble and, thus, more readily deposit and build up in the lungs and pleural membrane where their presence can lead to inflammation and other health problems. ${ }^{34}$ Dose refers to the amount of fiber particles to which a subject has been exposed.

How do HARNs resemble asbestos fibers? Many HARNs possess fibrous dimensions similar to asbestos fibers, as well as enhanced chemical reactivity and biopersistence. ${ }^{30} \mathrm{CNTs}$ may pose a potential health risk during production, and their fibrous shape raises the possibility that they may have a toxic effect like asbestos. Exposure to asbestos causes asbestosis, bronchogenic carcinoma, mesothelioma, pleural fibrosis, and pleural plaques, indicating that both the lungs and the pleura are targets. ${ }^{33}$ These qualities alerted the scientific community to the potential for exposure risks as early as 1998 , leading to numerous studies to determine the potential risk. ${ }^{35}$ A recent National Institute for Operational Safety and Health (NIOSH) review of 54 animal laboratory studies has shown that exposure to CNTs or carbon nanofibers (CNFs) results in adverse pulmonary effects such as inflammation, granulomas, or pulmonary fibrosis in animals and may, consequently, cause similar effects in humans. ${ }^{34}$ However, robust evidence as to the relationship between CNTs/CNFs and human pulmonary injury remains equivocal..$^{15}$ Therefore, an unknown potential exposure risk model continues to exist for researchers, industrial workers, and consumers.

However, asbestos types are not all the same in composition or pathogenicity, and the same holds true for CNTs; therefore, a cautionary approach is advised. As CNTs are manmade, they may be able to be fabricated into forms that reduce toxicity. A more detailed and comparative discussion of these materials is needed, but it is beyond the intended 
scope of this paper. The lesson that must be learned is that not all nanoparticles are equally pathogenic, as pathogenicity depends on the structure (diameter, size, conformation) and composition of the respective nanoparticle. The use of CNTs and other high aspect ratio nanomaterials at the workplace must be met with recommendations for safety and defined limits of occupational exposure to such nanoparticles.

\section{Extrapolation of HARN danger to researching any unknown material}

According to the National Institute of Environmental Health Sciences, researchers currently understand very little about the biologic or environmental effects of nanoscale materials. ${ }^{27}$ An example cited by the National Institute of Environmental Health Sciences states that workplaces often have no means to detect the presence of nanoparticles in the air - meaning workers may be critically exposed without their knowledge or that of the organization for which they work. ${ }^{27}$ While the field of nanotechnology has existed in theory since American physicist Richard Feynman's 1959 lecture “There's Plenty of Room at the Bottom", significant academic and industrial research leading to commercialization efforts did not occur until the early 2000 s. ${ }^{36,37}$ Fifteen or more years, therefore, have passed since the dawn of the Age of Nanotechnology without scientists clearly understanding the biologic risks and implications of nanomaterials - plenty of time for accidental, negligent, or willful exposure of university students to materials under study.

Nanotechnology, specifically the case of CNTs, provides ample evidence of how the research cohort studying an emerging technology dramatically outpaces the scientific community's ability to determine the health or environmental side effects of novel materials. This relationship is the catalyst that generates potential liability risk. As the numbers working with any novel material increase, so also does the probability of exposure - exposure that may cause injurious effects for a year, 2 years, 5 years, or even 20 years in the future. This systematic risk, inherent in the study of emerging science and technology, necessitates the understanding of the university's legal position in relation to its students as well as a review of the best practices that should be maintained or enacted to protect researchers involved in handling novel materials.

\section{How the law will treat three scenarios of exposure Legal theory governing student exposure to harmful materials}

Asbestos-related claims are generally brought under theories of products liability (where the plaintiff was not an employee of the defendant) or worker's compensation (where the plaintiff was an employee of the defendant). ${ }^{38-40}$ However, in general, universities are neither the manufacturer of any products containing the novel materials researched by their faculty nor are their students the employees of the laboratories in which they work. Unique situations do exist when a faculty member licenses his/her inventions through a technology transfer agreement and conducts his/her spinout company's operations on campus or when students are paid to work in a research environment. In most situations, the basic theory of law and cause of action available to an injured student will be a suit for negligence.

\section{Negligence}

There are five tenets to a prima facie case for negligence in tort law that a plaintiff student must prove to recover against his/her university or supervising faculty member: duty of care, breach of the duty of care, causation in fact, legal causation, and actual harm or loss. ${ }^{41}$

\section{Duty of care/standard of care}

A duty of care arises when a person or legal entity undertakes an affirmative action that could reasonably be expected to affect other people. ${ }^{42}$ In Texas and Georgia, a university student is considered an invitee at law upon a university's campus to whom the university and its employees owe a reasonable duty of care. ${ }^{19,43}$ In Nebraska, instructors have a legal duty to supervise their students in a nonnegligent fashion. ${ }^{20}$ Across the 50 states, general principles for determining the duty of care differ. Some states, such as Florida and Massachusetts, use the foreseeability test, meaning that a duty arises in the defendant if the harm to the plaintiff is foreseeable. ${ }^{44,45}$ In contrast, California pioneered the multifactor test for the duty of care that allows a set of public policy factors to negate the general duty of care that exists for all citizens under the California Civil Code. ${ }^{46,47}$ As of today, the vast majority of states follow some variation of the multifactor test. ${ }^{48}$

Standard of care refers to whether an individual or legal entity exercised the same caution as a reasonable person or legal entity under similar circumstances. ${ }^{42,49}$ What caution or standard of care, then, is required of universities and their faculty in relation to their students? The doctrine of in loco parentis does not apply to the relationship between college administrators, faculty, and adult university students. ${ }^{19,50,51}$ The duty to warn - such as in providing oversight and laboratory safety courses - attaches correlative to the student's own professional level. ${ }^{19,52}$ The duty to warn does not arise against generally known risks within a particular trade or profession. ${ }^{53}$ This standard of care is known as the sophisti- 
cated user doctrin, and more than half of all state courts have adopted this standard as their governing law. ${ }^{54}$

As such, the institutions will likely be held to different standards depending upon the educational level attained by a plaintiff. ${ }^{19,52}$ For instance, the plaintiff in Niles $v$. Board of Regents was a doctoral student who was injured in a laboratory accident after mixing chemicals together. ${ }^{19}$ The court held his prior education in chemistry should have either given him a professional understanding of or accorded him the wisdom to look up the potential reactions of certain chemicals before mixing them. ${ }^{19}$ As such, the plaintiff was found to have not met the evidentiary standard to prove the defendant university breached its duty of care. ${ }^{19}$ By comparison, a university would owe an undergraduate student a higher standard of care because undergraduates lack the formal training and technical expertise of a graduate students such as the plaintiff in Niles. ${ }^{52}$

\section{Breach of the duty of care}

The governing rule in the USA for breach of duty of care is the hand rule which states that the defendant breaches his/her duty to provide against injury when the probability and severity of resulting injuries outweighs the burden of providing adequate precaution. ${ }^{55}$ It is a balancing test that, ultimately, would weigh the expense - finances, labor hours, and so on - necessary to avoid student exposure to novel materials against the probability that exposure would result in injury and the severity of the resultant injury.

In $F u v$. State, a Nebraska doctoral student in chemistry sued his university after being injured in a laboratory explosion, and the trial court found his professor's lackluster supervision to constitute a breach of the supervisor's duty of care. ${ }^{20}$ Compared to the foreseeable risk and potential severity of injury caused by laboratory explosions when researching chemistry, the Nebraska Supreme Court found the burden of expecting the supervising professor to provide adequate time, instruction, and laboratory supervision to students pursuing dangerous experiments de minimis at best. ${ }^{20}$ While a more constructive argument might be made regarding the foreseeability of injury from future novel materials, in the case of HARNs - where numerous studies have linked exposure to the risk of serious pulmonary injury in various animal models, and government agencies are urging workplace precaution - courts will likely follow the Fu precedent. When presented with a student dying of mesothelioma or lung cancer, they will hold defendant universities liable where reasonably inexpensive safety measures could have prevented exposure.

\section{Causation}

In proving negligence, a plaintiff student must show that the breach of duty by the university or university faculty was both the direct and the proximate cause of the harm. ${ }^{41}$ To be the direct cause, the accidental, negligent, or willful act must have been necessary in order for the harm to result; in other words, the harm would not have occurred but for the breach of duty. ${ }^{41}$

"Proximate cause is defined as the point at which legal responsibility for harm arising from a defendant's act may be established by evidence such that the defendant's negligent act or failure to act was a substantial factor in bringing about the plaintiff's harm". ${ }^{56,57}$ To be the proximate cause, the breach of duty must meet the burden of one of three tests depending on the venue of the case. Under the foreseeability test - the most common test - the plaintiff must prove that the harm was foreseeable to arise from the actions of the defendant. ${ }^{58,59}$ Under the minority direct causation rule, if the breach can be causally linked to the harm in question, then it is the proximal cause unless a superseding intervening cause takes place between the breach and the harm. ${ }^{59,60}$ Finally, New York State uses a test called harm within the risk. According to this rule promulgated by Benjamin Cardozo, the plaintiff must be within a class of persons reasonably foreseeable to be injured by the defendant's act in order for the defendant's act to have been the proximate cause of plaintiff's injury. ${ }^{61}$

In $\mathrm{Fu}$, while the court determined the graduate student's supervising faculty member negligent, it also determined that this negligence was not the proximate cause of the student's injury. ${ }^{20}$ Despite the professor's negligent monitoring, the court found that even had the professor monitored properly, it would not have been enough to make the professor aware that the plaintiff would attempt the dangerous experiment on the day in question, thus offering the professor an opportunity to prevent disaster. ${ }^{20}$ While this Nebraska court uses the foreseeability test in determining the proximate cause, it could just have easily deigned the plaintiff's negligence in not researching the chemicals he was using before experimenting as a superseding intervening cause under the direct causation rule, similar to the outcome in Niles. ${ }^{19,20}$ Proving causation in any HARN or novel material litigation will likely require expert testimony and will hinge on close factors such as whether the student was exposed while conducting research for a professor or for his/her own purposes (thesis/doctoral research) as well as whether these facts can be proven many years after the exposure takes place.

\section{Actual harm and damages}

In order to recover under a theory of negligence, a plaintiff must prove he/she suffered an actual harm or incurred an 
actual loss. ${ }^{41}$ This means the student must prove the actual damages he/she has suffered because of the defendant's actions - physical, economic, or noneconomic.

Should a plaintiff student reach this stage of a trial, the defendant university's counsel will likely be limited to contending the amount of general damages - noneconomic damages such as loss of consortium or pain and suffering - as the majority of damages associated with the injury - medical bills and lost wages - will be easy to document. ${ }^{62}$ In the case where the negligent act was willful or reckless - such as knowingly disregarding university or Occupational Safety and Health Administration (OSHA) safety protocols for expediency - a court would potentially grant punitive damages to a student plaintiff as well. ${ }^{63}$

\section{Worker's compensation}

In certain instances, students researching novel materials in university facilities may also count as employees of the institution or a faculty-owned company operating on campus. For reference, Black's Law Dictionary defines an employee as "a person in the service of another under any contract of hire, express or implied, oral or written, where the employer has the power or right to control and direct the employee in the material details of how the work is to be performed". ${ }^{64}$ Though the question of what constitutes an employee is a contentious issue, control is central to any analysis. ${ }^{65}$ When determining whether a student worker is an employee, universities should consider to what extent supervisory faculty oversee and dictate how research is undertaken. ${ }^{65}$ As greater latitude is afforded to the student, the likelihood the student can qualify as an independent contractor instead of an employee increases. ${ }^{65}$ One simple rule of thumb for any organization is as follows: if the worker has been issued a W-2 form for his/her work, then the organization is acknowledging $\mathrm{him} /$ her as an employee. ${ }^{66}$

\section{Arising out of prong}

Where a student qualifies as an employee of a university or faculty-owned business, that student may be able to bring a claim for compensation under state worker's compensation laws, depending on underlying state law. The basic rule of worker's compensation law covers injuries arising out of and in the course of employment. ${ }^{67}$ While insurance pays worker's compensation claims, claims cause insurance rates to go up, so, universities may want to fight claims that are marginal. ${ }^{68,69}$

In general, arising out of employment means the type of risk that the plaintiff student was exposed to that resulted in their injury was the one he/she was exposed to due to his/ her employment. ${ }^{67}$ As an example, many nanoparticles are naturally occurring and medical science suspects nanoparticle exposure to be a factor in the development in a number of diseases. ${ }^{28}$ All people are exposed to the systematic risk of naturally occurring nanoparticles simply by breathing everyday. ${ }^{28}$ By comparison, where a plaintiff shows he/she have developed a disease known to be caused by an artificial class of chemicals - chemicals he/she once researched in a laboratory setting - the risk of exposure leading to their injury can only be factually arisen "out of" his/her employment.

\section{In the course of prong}

In order to arise in the course of employment, an injury must occur during the period of employment, at a location an employee reasonably may be, and while fulfilling job duties or activities incidental to his/her duties. ${ }^{67}$ In most instances, the period of employment will be easy to document through institutional or tax records. A more difficult issue may arise in documenting whether the exposure leading to injury occurred during the period of employment in cases where the plaintiff student worked in laboratories where the conditions for exposure existed as both employee and nonemployee. This fact pattern may arise when a student researcher is employed by a faculty start-up, but also uses university laboratory space to conduct research projects related to theses or dissertations. This fact pattern may also be a point of contention where dual roles exist in terms of the fulfilling job duties prong of the test; the defendant may contend that students who could have been exposed while conducting research in pursuance of their Master's thesis or doctoral dissertation were not engaged in job-related functions.

The location prong will not generally constitute a point of contention when exposure occurs in a university laboratory. However, the issue location may raise is one of who is the proper defendant against which a plaintiff student should file a worker's compensation claim. Where a faculty member licenses university-owned technology and operates a spinout company on campus - through either a formal agreement to rent laboratory space or an informal understanding allowing the use of laboratory space for company research and development - there may be an issue of on whose premises the injury took place. If a formal agreement does not exist, it may be possible to argue that the work done as an employee of the faculty member's company does not meet the requirements for worker's compensation as the work would not have been conducted upon company property or leasehold. 


\section{Aggravation claims}

It is important for universities and their faculty to understand that worker's compensation law may not bar further lawsuits depending upon the circumstances under which exposure occurred. A cause of action for aggravation of a disease exists where an employer fraudulently conceals a disease or disability. ${ }^{39,70}$ The action required exceeds failure to warn of potential harm from exposure where knowledge exists, such as detecting that a student has begun to develop some sort of disease due to exposure to a novel material and then concealing this fact and inducing the student to return to an environment risking greater exposure. ${ }^{70}$ While research institutions or their faculty are less likely to undertake obfuscating actions similar to asbestos or tobacco manufacturers, it is important for universities to understand all avenues of potential liability in order to insure against them.

\section{Environmental safety liability}

Additionally, universities, like any organization, are compelled to act under OSHA guidelines, OSHA-approved state plans, or local state laws governing workplace safety - whichever the general counsel determines to cover their institution. Student plaintiffs, exposed as students or employees, cannot bring a private cause of action under OSHA. ${ }^{71}$ However, violations of these guidelines uncovered during student litigation could result in further liability in the nature of fines and injunctions. ${ }^{72}$ Arizona, Arkansas, California, Connecticut, and Illinois law also affords injured workers a separate cause of action or enhanced award when OSHA violations occur. $^{73}$

\section{Defenses}

\section{Contributory or comparative negligence}

Contributory negligence acts as an affirmative defense for a tortfeasor and completely bars recovery for negligent acts. ${ }^{74}$ However, it is available in only a small number of US states. ${ }^{75}$ Comparative negligence functions as a partial defense and reduces a tortfeasor's liability according to the plaintiff's relative fault in causing his/her injuries. ${ }^{75}$

Many instances may occur that could result in a finding of contributory or comparative negligence upon the part of a plaintiff student. The student failed to wear a breathing mask or properly operate a ventilation hood while working with the novel material. The student did not complete a required laboratory safety course before conducting the laboratory work that resulted in exposure. Any deviation from proper protocol could be argued successfully to have contributed to the plaintiff's injury. ${ }^{76}$

\section{Statutes of limitation}

Statutes of limitation in a university's underlying state jurisdiction may act to bar recovery by a student plaintiff under certain circumstances. ${ }^{77}$ Given that the type of injury and the time between exposure and discovery are an unknown in this paper, it is difficult to predict how these laws - or future versions - may function. However, in the case of asbestos exposure - to which HARNs compare - courts currently start the clock on the statute of limitations from when discovery of the injury (asbestosis, mesothelioma, and so on) and of its source (working with asbestos) occurs. ${ }^{76-78}$ As such, the statute of limitations will be unlikely to bar recovery.

\section{Scenario I}

\section{Accidental exposure}

In this scenario, a typical student is working in a laboratory setting at a university under the direction of a faculty member researching a novel material with unknown health effects such as HARNs. During the course of his/her study, the student is accidentally (read: nonnegligently) exposed to the novel material in a quantity significant enough that a severe health problem develops in the short or long term, such as mesothelioma.

\section{Liability}

Where the university and its faculty are nonnegligent in their duties to exposed students, no tortious liability will accrue. However, workers' compensation law is not based on fault; it is a system of insurance. Where the injured student can successfully claim to have counted as a university or faculty startup employee during exposure, the student will be able to bring a claim for workers' compensation - provided, of course, that the university or faculty business in question is properly covered. As there is no question here of intentional or reckless behavior, there is no liability for punitive damages or acceleration under state statutes for violation of workplace safety protocols.

\section{Scenario II \\ Negligent exposure}

In this scenario, a typical student is working in a laboratory setting at a university under the direction of a faculty member researching a novel material with unknown health effects, such as HARNs. During the course of their study, the student 
is exposed to the novel material in significant quantities due to negligence on the part of his/her supervising faculty member, another university employee, or a fellow student. In the short or long term, they develop a severe health problem such as mesothelioma as a result.

\section{Liability}

In this scenario, the plaintiff is able to prove that negligence on the part of another actor resulted in his/her injuries. In the fact pattern where the negligent actor is a faculty member or other university employee, the university will be liable in tort for damages, provided the negligence is shown to have been the cause of the plaintiff's injuries. There may be significant debate on this point scientifically, given that all people are exposed to nanoparticles on a daily basis and because it may be difficult to prove the specificity of exposure leading to injury, unless exposure occurred on a daily basis as in asbestos worker lawsuits. Where the negligent party is another student, the university's liability will hinge on whether the supervising faculty member was negligent in his/her supervision of the negligent student. If the faculty member was not negligent, then the university cannot be liable and the student would have to bring a suit solely against the fellow student. As in the prior scenario, workers' compensation will be available to students who qualify as employees at the time of exposure.

Where negligent (but not willful) violations of workplace safety guidelines are part of the findings of fact related to the negligence lawsuit, some states may accelerate recovery for the plaintiff and fines may be levied upon the institution in question. Unlike the prior scenario where the plaintiff could only bring a worker's compensation claim, all standard defenses will be available to the university to fight this negligence lawsuit.

\section{Scenario III \\ Willful exposure}

In this scenario, a typical student is working in a laboratory setting at a university under the direction of a faculty member researching a novel material such as HARNs. During the course of his/her study, the student is exposed to the novel material in significant quantities due to willful or reckless action on the part of the supervisory faculty member, another university employee, or a fellow student. In the short or long term, they develop a severe health problem such as mesothelioma as a result. While this scenario may seem difficult to fathom in academia, risk-taking behavior can arise in all professions - out of expediency, laziness, or hubris - resulting in harm to self or others.

\section{Liability}

This scenario posits the fact pattern of intentional behavior causing the plaintiff student's exposure. Where the exposure is willful - such as a professor ordering his/her students to undertake experiments through or under conditions that will expose them to materials against established protocols such as safety guidelines - courts may grant the plaintiff punitive damages in addition to compensatory damages. In extraordinary cases where the behavior was intentional, a court may uphold a plaintiff's cause of action for battery rather than simple or gross negligence. Additionally, defense theories that apportion blame to the plaintiff, such as contributory or comparative negligence, are not available when the defendant is shown to have behaved in an intentional manner. Where the party at fault is a fellow student rather than a university employee, courts will consider the fact that the behavior was intentional in determining whether the supervisor was negligent. On the one hand, intentional behavior may be less foreseeable than a laboratory accident scenario. On the other hand, supervisors should understand the personalities and politics of their graduate students' relationships and be able to foresee actions their acolytes might take.

As in each scenario, student employees will be able to bring a workers' compensation claim and in states where such statutes exist, intentional behavior that violated workplace safety guidelines will accelerate these claims. Further, a defendant university guilty of intentional violation of these standards will likely face fines from federal or state officials.

\section{Conclusion}

\section{Recommended courses of action by universities}

\section{Centers for Disease Control (CDC) safety protocols} for nanoscale materials

As an immediate precaution when students and faculty are working with novel materials, it is suggested that certain CDC safety protocols be enacted in university laboratoriess. After conducting a thorough review of the potential hazards of CNTs and CNFs, the National Institute for Occupational Safety and Health promulgated the following recommendations:

1. Control worker exposure to CNT and CNF below $1 \mu \mathrm{g} / \mathrm{m}^{3}$ $8 \mathrm{~h}$ time-weighted average, respirable fraction (elemental carbon) during a $40 \mathrm{~h}$ work week.

2. Conduct comprehensive exposure assessments as part of an overall hazard surveillance program.

3. Develop guidelines for selecting, installing, and evaluating engineering controls (e.g., local exhaust ventilation, dust collection systems). 
4. Educate and train workers on the recognition of potential exposures and in the use of good work practices in the handling of bulk CNT and CNF, as well as CNT- and CNF-containing materials.

5. Develop procedures for the selection and use of personal protective equipment (i.e., clothing, gloves, respirators).

6. Implement a medical surveillance program for workers potentially exposed to CNT or CNF with conduct of specific medical screening tests when warranted.

7. Conduct routine (e.g., annual) and systematic evaluation of worker exposure to CNT or CNF when there is a process change in how CNTs or CNFs are manufactured or handled.

8. Encourage workers to wash hands before eating, smoking, or leaving the worksite.

9. Establish facilities for showering and changing clothes, with separate facilities for storage of nonwork clothing, to prevent the inadvertent cross-contamination of other areas (including take-home). ${ }^{15}$

\section{Hold harmless agreements}

As further precaution against potential future liability given the uncertainty that novel materials present, it is suggested that universities require students at any academic level who will be working with novel materials whose health and environmental effects are unknown to sign hold harmless agreements. The hold harmless agreement acts as a release from liability should exposure result in injury and acknowledges an understanding of the risks involved in working with novel materials. ${ }^{79}$ Each student must be required to sign prior to being allowed to enter any laboratory environment where novel materials are worked with due to the potential for nanoparticles to be present in the air - even entering a research laboratory could result in accidental exposure.

The hold harmless agreement should describe the general nature of research pursued at the university - covering all novel materials that may be encountered - and include space within the form for the student's research advisor to fill in the course of study to be undertaken as well as any novel materials to be utilized during the study. The university should provide an opportunity for students to consult their university counsel regarding the agreement if desired where feasible. The university counsel should review underlying state law to ensure the agreement comports with local law.

\section{Insurance}

Because of the nature of novel materials, it may prove difficult for universities to make this calculus in the present to determine whether they will face potential liability in the future. Managing risks of unknown severity or probability is generally the realm of insurance carriers. According to Michael H Ginsberg, a partner at the major law firm, Jones Day, insurance carriers such as Lloyd's of London have already begun to alter their policies to account for nanotechnology risks. ${ }^{80}$ Ginsberg forecasts policies that offer very limited coverage with very high premiums. ${ }^{80}$ In contrast, researchers at the University of Limerick have recently conducted a review of the insurance industry that suggested insurers are poorly informed about nanotechnology and far less concerned about its risks than scientists in the field. ${ }^{81}$ It is, therefore, recommended that universities purchase liability insurance where affordable and practicable before the industry catches up to researchers on nanoscale risks and hikes their premiums.

\section{Future research}

A systematic risk inherent in researching novel materials exists engendering a potential source of future liability for universities and their faculty. This paper analyzes the potential causes of action that could stem from this liability. Further review of case law is necessary to determine the likelihood that courts will hold injuries from exposure to novel materials as foreseeable or not. In the case of asbestos and many other products liability lawsuits, the tortfeasor was shown to have been aware of the risk his/her product or novel material posed to workers before exposure took place. ${ }^{76}$ While all instances of products liability do not work this way, more research is necessary to predict whether courts will find materials such as HARNs analogous to asbestos.

\section{Disclosure}

The authors report no conflicts of interest in this work.

\section{References}

1. Greek R, Shanks N, Rice M. The history and implications of testing thalidomide on animals. J Phil Sci L. [serial on the Internet]. 2011 [cited 2015 May 20];11:20. Available from: http://jpsl.org/archives/history-andimplications-testing-thalidomide-animals/. Accessed May 20, 2015.

2. Fintel B, Samaras T, Carias E. The thalidomide tragedy: lessons for drug safety and regulation. Helix. [serial on the Internet]. 2009 [cited 2015 May 15]:3. Available from: https://helix.northwestern.edu/article/ thalidomide-tragedy-lessons-drug-safety-and-regulation. Accessed May 15, 2015.

3. Russell M. Thalidomide victims receive $\$ 89 \mathrm{~m}$ compensation. The Sydney Morning Herald. [serial on the Internet]. 2014 [cited 2015 May 15]:5. Available from: http://www.smh.com.au/national/thalidomidevictims-receive-89m-compensation-20140206-325pf.html. Accessed May 15, 2015.

4. BBC News. Thalidomide: Britons launch legal case. BBC News. [serial on the Internet]. 2014 [cited 2015 May 15]:3. Available from: http:// www.bbc.com/news/uk-27708295. Accessed May 15, 2015.

5. Peltzman S. An Evaluation of Consumer Protection Legislation: The 1962 Drug Amendments. The Journal of Political Economy. 1973: 81(5);1051. 
6. Mohan M, Trump B, Bates M, Linkov I. Integrating legal liabilities in nanomanufacturing risk management. 2012. Environ Sci Technol. 2012;46(15):7955-7962.

7. Strand R, Kjølberg K. Regulating nanoparticles: the problem of uncertainty. 2011. Eur J L Technol. [serial on the Internet]. 2011 [cited May 20, 2015] 2(3):10. Available from: http://ejlt.org/article/view/88/157. Accessed May 20, 2015.

8. Wernette R. Nanoparticles: new frontier for product liability mass torts/ class action claims. Toxics L Rep. 2010;(11):1.

9. AIP.org. [Nonprofit Organization on the Internet]. American Institute of Physics; Marie Curie and the science of radioactivity. [cited 2015 May 15]:3. Available from: http://history.aip.org/history/exhibits/curie/ radinst3.htm. Accessed May 15, 2015.

10. Strong v. E.I. DuPont de Nemours Co., Inc., 667 F.2d 682, 687 (8th Cir. 1981). Available from https://casetext.com/case/strong-v-e-i-dupont-denemours-co-inc. Accessed July 5, 2017.

11. Avila v. Citrus Community College Dist., 131 P.3d 383, 41 Cal. Rptr. 3d 299, 313 (2006). Available from https:/www.courtlistener.com/ opinion/2575823/avila-v-citrus-community-college-. Accessed July 5, 2017.

12. Nano.gov. NNI supplement to the president's 2015 budget. Ntl Nanotechnology Initiative [governmental entity]. 2014 [cited 2015 May 15]:2. Available from: http://www.nano.gov/node/1128. Accessed May $15,2015$.

13. GAO.gov [governmental entity on the Internet]. Government accountability office; nanotechnology: improved performance information needed for environmental, health, and safety research. [cited 2015 May 15]:84. Available from: http://www.gao.gov/products/GAO-12-427. Accessed May 15, 2015.

14. Donaldson K, Murphy F, Schinwald A, Duffin R, Poland CA. Identifying the pulmonary hazard of high aspect ratio nanoparticles to enable their safety-by-design. 2011. Nanomedicine. 2011;6(1):143-156.

15. CDC.gov [governmental entity on the Internet]. National Institute for Occupational Safety and Health; occupational exposure to carbon nanotubes and nanofibers. [cited 2015 May 21]:184. Available from: http:// www.cdc.gov/niosh/docs/2013-145/pdfs/2013-145.pdf. Accessed May 21, 2015.

16. PCI.com. Report forecasts strong growth in nanotechnology market. PCI Magazine. [serial on the Internet]. 2013 [cited 2015 May 18]:2. Available from: http:/www.pcimag.com/articles/97953-report-forecasts-stronggrowth-in-nanotechnology-market. Accessed May 18, 2015.

17. Malanowski N, Heimer T, Luther W, Werner M, editors. Growth Market Nanotechnology: An Analysis of Technology and Innovation. WileyVCH. Hoboken, NJ. 2006.

18. NSF.gov. Market report on emerging nanotechnology now available. Ntl Sci Found. [governmental entity]. 2014 [cited 2015 May 18]:2. Available from: https://www.nsf.gov/news/news_summ.jsp?cntn_id=130586. Accessed May 18, 2015.

19. Niles v. Bd. of Regents of Univ. Sys. of Ga., 473 S.E. 2d 173, 174-5, 222 Ga. App. 173 (1996). Available from http://www.leagle.com/ decision/1996646473SE2d173_1642/NILES\%20v.\%20BD.\%20 OF\%20REGENTS\%20OF\%20UNIVERSITY\%20SYSTEM\%20 OF\%20GEORGIA/. Accessed July 5, 2017.

20. Fuv. State, 643 N.W. 2d 659, 668-9, (Neb. 2002). Available from https:// www.courtlistener.com/opinion/2121164/fu-v-state/. Accessed July 5, 2017.

21. ETC Group. Nanotech's "second nature" patents: implications for the Global South. Communiqués. [serial on the Internet]. 2005 [cited 2015 May 16]:36. Available from: http://www.nanowerk.com/nanotechnology/reports/reportpdf/report7.pdf. Accessed May 16, 2015.

22. Butt M. Insurance economics and legal systems. 2004. Geneva Pap Risk Insur. 2004;29(1):5-13.

23. Evans H. Thalidomide: how men who blighted lives of thousands evaded justice. Guardian. [serial on the Internet]. 2014 [cited 2015 May 15]:14. Available from: http://www.theguardian.com/society/2014/nov/14/-spthalidomide-pill-how-evaded-justice. Accessed May 16, 2015.
24. DW. Spanish birth defect victims win damages from German drug maker. Deutsche Welle. [serial on the Internet]. 2013 [cited 2015 May 16]:2. Available from: http://www.dw.de/spanish-birth-defect-victimswin-damages-from-german-drug-maker/a-17242253. Accessed May 16, 2015.

25. Smith-Spark L. Survivor: German firm's apology for birth defects drug 'not enough'. $C N N$. [serial on the Internet]. 2012 [cited 2015 May 16]:3. Available from: http://www.cnn.com/2012/09/01/health/ germany-thalidomide-apology/. Accessed May 162015.

26. Morris J. America's toxic legacy may leave behind a half-million deaths. Intl Consortium Invest Journalists [serial on the Internet]. 2010 [cited 2015 May 16]:5. Available from: http://www.icij.org/project/dangersdust/americas-toxic-legacy-may-leave-behind-half-million-deaths. Accessed May 16, 2015.

27. Niehs.nih.gov [governmental entity on the Internet]. RTP: National Institute of Environmental Health Sciences; Nanomaterials [cited 2015 May 18]:10. Available from: http:/www.niehs.nih.gov/health/topics/ agents/sya-nano/. Accessed May 18, 2015.

28. Buzea C, Pacheco I, Robbie K. Nanomaterials and nanoparticles: sources and toxicity. Biointerphases. 2007;2(4):MR17-MR71.

29. Stark W, Stoessel P, Wohlleben W, Hafner A. Industrial applications of nanoparticles. Chem Soc Rev. 2015;44(16):5793-5805.

30. Poland C, Duffin R, Kinloch I, et al. Carbon nanotubes introduced into the abdominal cavity of mice show asbestos-like pathogenicity in a pilot study. 2008. Nat Nanotechnol. 2008;3(7):423-428.

31. Collins P, Avouris P. Nanotubes for electronics. 2000. Sci Am. 2000;283(6):62-69.

32. Poland C, Duffin R, Donaldson K. High aspect ratio nanoparticles and the fibre pathogenicity paradigm. In: Sahu S, Casciano D, editors. Nanotoxicity: From In Vivo and In Vitro Models to Health Risks. Chichester, West Sussex; Wiley; 2009:61-80.

33. Donaldson K, Murphy F, Duffin R, Poland CA. Asbestos, carbon nanotubes and the pleural mesothelium: a review of the hypothesis regarding the role of long fibre retention in the parietal pleura, inflammation and mesothelioma. Part Fibre Toxicol. 2010;7:5.

34. CDC.gov [governmental entity on the Internet]. National Institute for Occupational Safety and Health; Asbestos fibers and other elongate mineral particles: state of the science and roadmap for research [cited 2015 May 21]:174. Available from: https://www.cdc.gov/niosh/ docs/2011-159/pdfs/2011-159.pdf. Accessed May 21, 2015.

35. Service R. Nanotubes: the next asbestos? 1998. Science. 1998;281(5379):941-942.

36. Feynman R. Plenty of Room at the Bottom. MSU.edu [university website]. 1959 [cited 2015 May 20]:7. Available from: http://www.pa.msu. edu/ yang/RFeynman_plentySpace.pdf. Accessed May 20, 2015.

37. 21 st Century Nanotechnology Research and Development Act, 15 USC $\S 7501$ (2003).

38. White M. Asbestos and the future of mass torts. J Econ Persp. 2004;18(2):183-204.

39. Millison v. E.I. DuPont de Nemours \& Co., 501 A.2d 505, 101 N.J. 161 (1985).

40. Johns-Manville Products Corp. v. Superior Ct., 612 P.2d 948, 27 Cal. 3d 465 (1980).

41. Owen D. The five elements of negligence. 2007. Hofstra L Rev. 2007;35(4):1671-1686.

42. Restatement (Second) of Torts $\S 302$.

43. Rawlings v. Angelo St. Univ., 648 S.W. 2d 430 (Tx. Ct. App. 1983).

44. Foley v. Boston Hous. Auth., 407 Mass. 640 (1990).

45. Kaisner v. Kolb, 543 So. 2 d 732 (Fla. 1989).

46. Cal. Civ. Code $\S 1714$ (1970).

47. Rowland v. Christian, 69 Cal. 2d 108 (1968).

48. Cardi W. The hidden legacy of palsgraf: modern law in microcosm. 2011. Boston UL Rev. 2011;91:1873-1913.

49. Vaughan v. Menlove, 3 Bing. N.C. 467 (1837).

50. Bradshaw v. Rawlings, 612 F.2d 135 (3rd Cir. 1979).

51. Dixon v. Alabama, 294 F.2d 150 (5th Cir. 1961). 
52. Kiser v. Snyder, 205 S.E. $2 d 619$ (N.C. Ct. App. 1974).

53. Eyster v. Borg-Warner Corp., 206 S.E. 2d 668, 131 Ga. App. 702 (1974).

54. Sungaila MC, Mayer K. Limiting manufacturer's duty to warn: the sophisticated user and purchaser doctrines. Def Couns J. 2009;76(2):196-202.

55. U.S. v. Carroll Towing Co., 159 F.2d 169 (2nd Cir. 1947).

56. Hamil v Bashline, 392 A.2d 1280, 481 Pa. 256 (1978).

57. Prosser W. Law of Torts. 4th ed. West. 1971.

58. The Wagon Mound no 1, A.C. 388 (Austral. 1961).

59. Emanual S. Torts. 6th ed. Emanuel Pub Corp.; Larchmont, NY. 2001.

60. In re Polemis \& Furness, Withy \& Co, 3 K.B. 560 (1921).

61. Palsgrafv Long Is. R.R., 162 N.E. 99, 248 N.Y. 339, 225 N.Y.S. 412 (1928).

62. Sanders J. Reforming general damages: a good tort reform. Roger Williams U L Rev. 2008;13(1):115-153.

63. Landes W, Posner R. New light on punitive damages. Regulation. 1986:33-36.

64. Black HC. Black's Law Dictionary. 6th ed. Springer; Berlin, Germany. 1991.

65. Muhl C. What is an employee? the answer depends on the federal law. Monthly Lab Rev. 2002;3-11.

66. IRS.gov [governmental entity on the Internet]. Internal revenue service; Topic 752 - forms W-2 and W-3 - where, when and how to file. [cited 2015 May 18]:2. Available from: http://www.irs.gov/taxtopics/tc752. html. Accessed May 18, 2015.

67. Larson L, Larson A. Workers' Compensation Law: Cases, Materials, and Text. 4th ed. LexisNexis; New York, NY. 2008.

68. Colorado.gov [governmental entity on the Internet]. Colorado dept of labor \& employment; Employer's guide [cited 2015 May 17]:44. Available from: https://www.colorado.gov/pacific/sites/default/files/ Employers_Guide_2015.pdf. Accessed May 17, 2015.

69. WA.gov. Rates for workers compensation. Washington State Dept Labor Ind. [governmental entity]. 2015 [cited 2015 May 18]:6. Available from: $\mathrm{http}: / / \mathrm{www}$. Ini.wa.gov/claimsins/insurance/ratesrisk/check/rateshistory/. Accessed May 18, 2015.

70. Johns-Manville Products Corp. v. Superior Ct., 612 P.2d 948, 27 Cal. 3d 465 (1980). Available from: http://scocal.stanford.edu/opinion/johnsmanville-products-corp-v-superior-court-30572. accessed June 23, 2016.
71. Jeter v. St. Regis Paper Co., 507 F.2d 973 (5th Cir. 1975). Available from:http://openjurist.org/507/f2d/973/jeter-v-st-regis-paper-co. Accessed June 23, 2016.

72. 29 USC $\S 666$ (1970). Available from:https://www.law.cornell.edu/ uscode/text/29/666. Accessed June 23, 2016.

73. Swanson R. Enhanced worker's compensation awards or penalties based on safety violations or employer misconduct. Am Bar Assoc. [trade association on the Internet]. 2009 [cited 2015 May 19]:35. Available from: http://www.americanbar.org/content/dam/aba/administrative/ labor_law/meetings/2009/ac2009/086.authcheckdam.pdf. Accessed May 19, 2015.

74. Pope \& Talbot, Inc. v. Hawn, 346 U.S. 406 (1953). available from:https:// supreme.justia.com/cases/federal/us/346/406/case.html. Accessed June 23, 2016.

75. Wickert G. Understanding comparative fault and contributory negligence and joint \& several liability. Claims $J$. [serial on the Internet]. 2013[cited 2015 May 20]:3. Available from: http://www.claimsjournal. com/news/national/2013/09/05/235755.htm. Accessed May 20, 2015.

76. Borel v. Fibreboard Paper Products Corp., 493 F.2d 1076 (5th Cir. 1973). Available from:https://tshaonline.org/handbook/online/articles/jrb01. Accessed June 23, 2016.

77. Davis F. Tort liability and the statutes of limitation. 1968. Mo L Rev. 1968;33(2):171-228.

78. Nolan v Johns-Manville Asbestos, 421 N.E. 2d 864, 85 Ill. 2d 161 (1981). Available from:http://law.justia.com/cases/illinois/supremecourt/1981/52484-6.html. Accessed June 23, 2016.

79. LSU.edu. [University Website]. LSU admin services and risk management; Hold harmless \& indemnification agreements [cited 2015 May 18]. Available from: https://sites01.1su.edu/wp/riskmgt/holdharmless-agreements. Accessed May 18, 2015.

80. Ginsberg M. Insurance coverage for nanoproducts. Pract Perspect Nanotechnol. 2010 [cited 2015 May 16]:6. Available from: http://www. jonesday.com/practiceperspectives/nanotechnology/insurance_coverage.html. Accessed May 16, 2015.

81. Baublyte L, Mullins M, Murphy F, Tofail S. Insurance market perception of nanotechnology and nanomaterials risks. 2014. Geneva Assoc Risk Manage Newsletter. 2014;54:9-14.
Medicolegal and Bioethics

\section{Publish your work in this journal}

Medicolegal and Bioethics is an international, peer-reviewed, open access journal exploring the application of law to medical and drug research and practice and the related ethical and moral considerations. The journal is characterized by the rapid reporting of reviews, case reports, guidelines and consensus statements, original research

\section{Dovepress}

and surveys. The manuscript management system is completely online and includes a very quick and fair peer-review system. Visit http://www.dovepress.com/testimonials.php to read real quotes from published authors. 